\title{
Association between Intermountain Risk Score and long-term mortality with the transcatheter aortic valve implantation procedure
}

\author{
Emre Özdemir, Şaban Esen, Sadık Volkan Emren, Mustafa Karaca, Cem Nazlı \\ Department of Cardiology, Ataturk Education and Research Hospital, Katip Celebi University, Izmir, Turkey
}

\section{Editorial}

by Conrotto et al.

see p. 1193

\author{
Correspondence to: \\ Emre Özdemir, MD, \\ Department of Cardiology \\ Ataturk Education and Research \\ Hospital, \\ Katip Celebi University, \\ Basın Sitesi, Mahallesi, Atatürk \\ Eğitim Hst. No. 106, 35150 \\ Karabağlar/Izmir, Turkey, \\ phone: +90232 2444444 , \\ e-mail: \\ emreozdemir27@yahoo.com.tr \\ Copyright by the Author(s), 2021 \\ Kardiol Pol. 2021; \\ 79 (11): 1215-1222 \\ DOI: 10.33963/KP.a2021.0120 \\ Received: \\ March 1, 2021 \\ Revision accepted: \\ September 28, 2021 \\ Published online: \\ September 28, 2021
}

\begin{abstract}
A B STR A C T:
Background: Since its first introduction, the spectrum and frequency of use of transcatheter aortic valve implantation (TAVI) have increased throughout the world. Therefore, it is crucial to determine which patients are at high mortality risk with TAVI. The Intermountain Risk Score (IMRS) is a score calculated from laboratory parameters. This study aimed to determine the long-term mortality of TAVI patients using the IMRS and to compare it with traditional scoring systems.
\end{abstract}

Methods: The study included a total of 133 patients undergoing TAVI at our hospital from 2010 to 2019. Demographic data, co-morbid diseases, echocardiographic and laboratory parameters were collected retrospectively. The performance of IMRS was assessed as compared to the mortality determined in the overall patient population.

Results: During the follow-up, $54.9 \%$ of patients (60 patients) (Group 1) survived; the mortality in Group 2 (60 patients) was $45.1 \%$. The survival period had a mean of $1433( \pm 124)$ days. The mean IMRS was $1.67(0.7)$ in Group 1 and $2.33(0.72)$ in Group $2(P<0.001)$. In multivariable analyses, only high risk of IMRS (hazard ratio [HR], 3.430; 95\% confidence interval [CI], 1.537-7.653; $P=0.003$ ) and EuroSCORE II (HR, 1.141; $95 \% \mathrm{Cl}, 1.011-1.288 ; P=0.03)$ independently predicted long-term mortality.

Conclusions: From the evaluation of all laboratory and echocardiography parameters, long-term mortality (>30 days) following the TAVI procedure can be said to be higher in patients with a high IMRS. The data from this study can be considered of value in demonstrating the clinical significance of IMRS calculation before the TAVI procedure.

Key words: Intermountain Risk Score, mortality, transcatheter aortic valve replacement

Kardiol Pol 2021; 79, 11: 1215-1222

\section{INTRODUCTION}

After the first demonstration of transcatheter aortic valve implantation (TAVI) in 2002 by Criber et al., this procedure came into widespread use for the treatment of severe aorta stenosis (SAS) [1, 2]. Globally, the TAVI procedure is an acceptable treatment for patients deemed to be at intermediate or high risk of symptomatic SAS (sSAS) for open-heart surgery [3]. Therefore, it is crucial to determine which patients would be at high risk prior to
TAVI. The literature reports 1-year mortality rates ranging between $6.7 \%$ and $14.5 \%$ [4].

Although the success of the procedure is linked to the surgeon's experience, the use of some risk parameters or risk scores may be beneficial for identyfying high-risk patients before TAVI. The European System for Cardiac Operative Risk Evaluation Score (EuroSCORE) and the Society of Thoracic Surgeons (STS) risk scores are the most commonly used and well-known traditional scoring systems for 
The answer as to which transcatheter aortic valve implantation (TAVI) patients will benefit in the long term does not depend on a single scoring system. Therefore, the Intermountain Risk Score (IMRS) can serve as a useful additional auxiliary scoring system.

TAVI. However, these scores were developed to predict perioperative mortality and morbidity for cardiac surgery $[5,6]$. Moreover, the use of these well-known traditional risk scores for TAVI risk stratification currently results in poor prediction values of TAVI outcomes [4, 7].

This study aimed to compare predictions of long-term mortality of TAVI patients provided by the Intermountain Risk Score (IMRS), echocardiographic/laboratory parameters, and other well-known traditional risk scores, namely EuroSCORE II and STS. Thus, this work aimed to evaluate the value of IMRS in the determination of long-term mortality and the applicability of its use for the selection of patients appropriate for TAVI.

\section{METHODS}

\section{Patient selection}

This retrospective study enrolled a total of 136 patients who underwent the TAVI procedure in a tertiary-level hospital between 2010 and 2019. Three patients were excluded from the study due to the lack of data on their hospitalization and follow-up. The decision to conduct TAVI was made for patients with sSAS and high surgical risk or contraindication to surgical valve replacement according to the international guidelines and the consensus of the local cardiology, cardiac surgery, and cardiac anesthesiology council.

\section{Data collection}

The following pre-procedural clinical status data on the patients were collected from their medical records: diabetes mellitus (DM, regulated blood glucose with at least one drug or diet), arterial hypertension (HT, regulated blood pressure with at least one drug or diet), coronary arterial disease (CAD, documented coronary lesion $>50 \%$ ), and atrial fibrillation ( $A F$, any documented atrial fibrillation period).

Pre and post-procedural data included serum hemoglobin, platelet count, creatinine, glomerular filtration rate (GFR), left ventricular ejection fraction (LVEF), left ventricular diastolic diameter (LVDD), left ventricular systolic diameter (LVSD), left atrial diameter (LA), interventricular septal diameter (IVS), posterior wall diameter (Pw), mitral valve insufficiency (MVI), aortic valve insufficiency (AVI), aortic valve peak gradient (PGR), aortic valve mean gradient (MGR), aortic valve area (AVA, calculated with planometry on transesophageal echocardiography), and systolic pulmonary arterial pressure. Contrast-induced nephropathy (CIN) was defined as a $25 \%$ increase in serum creatinine from baseline within 48 hours after contrast media administration.
A record was made of the procedural TAVI valve model and size, balloon post-dilatation requirement, cardiac pacemaker requirement, anesthesia type (general or sedoanalgesia), and transesophageal echocardiography (TEE) usage.

Data on postprocedural paravalvular aortic insufficiency (PAVI), follow-up time (number of days from the procedure to the final follow-up examination), the length of hospital stay (number of days from the procedure to discharge), in-hospital mortality, and LVEF, LVDD, LVSD, LA, IVS, Pw, MVI, AVI, PGR, MGR, systolic pulmonary arterial pressure, and PAVI values at 24 hours and 1 month were also recorded.

The IMRS and platelet decrease value (calculated as 'preprocedural - postprocedural platelet count') and occurrence of CIN were calculated retrospectively from the hospital records [8-10].

The IMRS, EuroSCORE II, and STS values were calculated from the hospital records at the time of the preoperative evaluation. The IMRS values were classified in groups of low, moderate, or high $[10,11]$.

If death had occurred, the date of the patient's death was checked from the national registration system, and survival was calculated as the number of days from the procedure to the date of death. The IMRS and the EuroSCORE II/STS were compared with mortality, with the expectation that IMRS may be a predictor of long-term mortality.

Approval for the study was granted by the Local Ethics Committee, and informed consent was obtained from all patients.

\section{Statistical analysis}

Statistical analyses were performed with the IBM Corp. Released 2017. IBM SPSS Statistics for Windows, Version 25.0. (IBM Corp., Armonk, NY, USA). The Kolmogorov-Smirnov test was performed to assess whether the data had a normal distribution. Continuous variables are presented as mean (standard deviation [SD]) and/or median (interquartile range $[\mathrm{IQR}]$ ) values and were compared with t-test and/or Mann-Whitney test values depending on the type of data distribution. Categorical variables are presented as numbers and percentages. Chi-square test and Fisher exact test were performed to compare categorical variables. Kaplan-Meier survival curve was used to determine survival rates and estimated life expectancy. Risk factors for mortality were first evaluated via univariate analyses. Independent predictors of long-term mortality were then identified via Standard Multivariable Cox regression analyses. A $P$-value $<0.05$ was considered statistically significant. 
Table 1. Clinical and laboratory parameters of patients. No statistical significance determined between the two groups

\begin{tabular}{|c|c|c|c|}
\hline Variable & $\begin{array}{l}\text { Survivors (Group 1) } \\
\qquad n=73\end{array}$ & $\begin{array}{l}\text { Non-survivors (Group 2) } \\
\qquad n=60\end{array}$ & $P$-value \\
\hline Age, years, mean (SD) & $78.38(7.1)$ & $78.90(7.9)$ & 0.69 \\
\hline Female gender, $\mathrm{n}(\%)$ & $44(60.3)$ & $35(58.3)$ & 0.82 \\
\hline Coronary artery disease, $\mathrm{n}(\%)$ & $64(87.7)$ & $51(85)$ & 0.34 \\
\hline Diabetes mellitus, $\mathrm{n}(\%)$ & $20(27)$ & $21(35)$ & 0.42 \\
\hline Arterial hypertension, n (\%) & $66(90.3)$ & $50(83)$ & 0.75 \\
\hline Atrial fibrillation, $\mathrm{n}(\%)$ & $16(21.9)$ & $16(26.7)$ & 0.32 \\
\hline Hemoglobin, g/dl, median (IQR) & $10.9(10.4-11.85)$ & $11.2(10.2-12.25)$ & $0.51^{\mathrm{a}}$ \\
\hline Creatinine, mg/dl, median (IQR) & $0.93(0.8-1.12)$ & $0.9(0.79-1.18)$ & $0.70^{\mathrm{a}}$ \\
\hline Glomerular filtration rate, $\mathrm{ml} / \mathrm{min} / 1.73 \mathrm{~m}^{2}$, mean (SD) & $69.50(21.8)$ & $68.54(25.6)$ & 0.85 \\
\hline Contrast-induced nephropathy, n (\%) & $10(13.7)$ & $9(15 \%)$ & 0.83 \\
\hline Pre-procedural platelet count, $\times 10^{9} / 1$, mean (SD) & $244.86(72.6)$ & $241.0(94.9)$ & 0.79 \\
\hline Post-procedural platelet count, $\times 10^{9} / \mathrm{l}$, median (IQR) & $121(91-174.5)$ & $125(80-157)$ & $0.36^{\mathrm{a}}$ \\
\hline
\end{tabular}

aMann-Whitney test performed IQR

Abbreviations: IQR, interquartile range; SD, standard deviation

Table 2. Echocardiography parameters of patients

\begin{tabular}{|c|c|c|c|c|}
\hline \multicolumn{2}{|c|}{ Variable } & $\begin{array}{l}\text { Survivors (Group 1) } \\
\qquad n=73\end{array}$ & $\begin{array}{l}\text { Non-survivors (Group 2) } \\
\qquad n=60\end{array}$ & P-value \\
\hline \multicolumn{2}{|c|}{$\begin{array}{l}\text { Pre-procedural left ventricular ejection fraction, \%, } \\
\text { median (IQR) }\end{array}$} & $60(50-60)$ & $60(53-60)$ & $0.443^{\mathrm{a}}$ \\
\hline \multicolumn{2}{|c|}{ Left ventricular diastolic diameter, mm, median (IQR) } & $46(44-50)$ & $47(44-51)$ & $0.708^{\mathrm{a}}$ \\
\hline \multicolumn{2}{|c|}{ Left ventricular systolic diameter, mm, median (IQR) } & $31(27-37)$ & $31(27-34)$ & $0.302^{\mathrm{a}}$ \\
\hline \multicolumn{2}{|c|}{ Left atrial diameter, mm, mean (SD) } & $44.71(7.5)$ & $44.79(6.5)$ & 0.94 \\
\hline \multicolumn{2}{|c|}{ Interventricular septal diameter, mm, median (IQR) } & $13(12-16)$ & $14(12.5-15)$ & $0.987^{\mathrm{a}}$ \\
\hline \multicolumn{2}{|c|}{ Posterior wall diameter, mm, mean (SD) } & $13.35(4.7)$ & $12.80(2.1)$ & 0.40 \\
\hline \multicolumn{2}{|c|}{ Aortic peak valvular gradient, mm Hg, median (IQR) } & $83(72.25-105.75)$ & $76(67.25-91)$ & $0.014^{\mathrm{a}}$ \\
\hline \multicolumn{2}{|c|}{ Aortic mean valvular gradient, mm Hg, mean (SD) } & $53.04(15.5)$ & $48.34(11.6)$ & 0.05 \\
\hline \multicolumn{2}{|c|}{ Aortic valve area, $\mathrm{mm}^{2}$, median (IQR) } & $0.8(0.72-0.93)$ & $0.87(0.73-0.92)$ & $0.77^{\mathrm{a}}$ \\
\hline \multicolumn{2}{|c|}{ Systolic pulmonary artery pressure, $\mathrm{mm} \mathrm{Hg}$, median (IQR) } & $40(30-55)$ & $40(30-52)$ & $0.906^{\mathrm{a}}$ \\
\hline \multirow[t]{3}{*}{ Aortic insuffiency, n (\%) } & Severe & $8(11)$ & $2(3.3)$ & \multirow[t]{3}{*}{0.17} \\
\hline & Moderate & $24(33)$ & $11(18)$ & \\
\hline & Mild & $29(40)$ & $37(62)$ & \\
\hline \multirow[t]{3}{*}{ Mitral insuffiency, $\mathrm{n}(\%)$} & Severe & $16(22)$ & $18(30)$ & \multirow[t]{3}{*}{0.41} \\
\hline & Moderate & $32(44)$ & $23(38)$ & \\
\hline & Mild & $23(31.5)$ & $(25)$ & \\
\hline
\end{tabular}

The intergroup difference in the aortic peak gradient was statistically significant but had no predictive value aMann-Whitney test performed IQR

Abbreviations: see Table 1

\section{RESULTS}

This work evaluated a total of 133 TAVI patients. The patients were separated into two groups according to mortality. The patients in Group $1(n=73)$ did not develop mortality during the follow-up period, whereas those in Group $2(n=60)$ did.

Their demographic and clinical characteristics are shown in Table 1. No difference was found between the groups in the baseline demographic, clinical, and laboratory parameters.

Female sex predominance, the mean age of the patients, the presence of $C A D, D M, H T$, and AF; occurrence of $\mathrm{CIN}$, preprocedural mean hemoglobin, mean serum creatinine, mean GFR, mean preprocedural platelet count, mean postprocedural platelet count, and decrease in platelet count were similar and differences were statistically non-significant between both groups (Table 1).

For the in-hospital post-procedural period, with both groups, there was no major bleeding. Except for the peak aortic gradient (mean [SD], 88.78 [22.72] mm Hg in Group 1; 79.17 [18.8] mm Hg in Group $2[P=0.01])$, the preprocedural echocardiographic parameters were similar in both groups (Table 2).

The mean TAVI valve size, the application of balloon post dilatation, cardiac permanent pacemaker implantation, the presence of postprocedural mild-moderate PAVI and procedural stroke, and the 1-month follow-up mean LVEF, median LVDD, median LVSD, mean LA, mean MGR, and mean sPAP were similar in both groups. Periprocedural TEE usage and the types of bioprosthetic valves used in 
Table 3. Procedural valve type, valve size and balloon dilatation; postprocedural echocardiograpic features and platelet count change; risk scores of patients. With the exception of the Intermountain Risk Score (IMRS), no statistical significance determined between the two groups

\begin{tabular}{|c|c|c|c|c|}
\hline & Variable & $\begin{array}{l}\text { Survivors (Group 1) } \\
\qquad n=73\end{array}$ & $\begin{array}{l}\text { Non-survivors (Group 2) } \\
\qquad n=60\end{array}$ & P-value \\
\hline \multirow[t]{3}{*}{ TAVI valve type } & Portico ${ }^{T M}, \mathrm{n}(\%)$ & $56(77)$ & $30(50)$ & \multirow[t]{3}{*}{0.006} \\
\hline & Core-Valve $^{\mathrm{TM}}, \mathrm{n}(\%)$ & $12(16)$ & $22(37)$ & \\
\hline & Edward-Sapiens $^{\mathrm{TM}}, \mathrm{n}(\%)$ & $5(7)$ & $8(13)$ & \\
\hline \multicolumn{2}{|c|}{ Balloon postdilatation, $\mathrm{n}(\%)$} & $30(41)$ & $16(27)$ & 0.09 \\
\hline \multirow[t]{7}{*}{ TAVI valve size, $\mathrm{n}(\%)$} & No. 21 & $5(6.8)$ & $5(8.3)$ & \multirow[t]{7}{*}{0.49} \\
\hline & No. 23 & $2(2.7)$ & $3(5)$ & \\
\hline & No. 25 & $7(9.6)$ & $10(16.7)$ & \\
\hline & No. 26 & $20(27.4)$ & $9(15)$ & \\
\hline & No. 27 & $33(45.2)$ & $30(50)$ & \\
\hline & No. 31 & $2(2.8)$ & $2(3.3)$ & \\
\hline & No. 34 & $4(5.5)$ & $1(1.7)$ & \\
\hline \multicolumn{2}{|c|}{ Mild-moderate paravalvular aortic insufficiency, n (\%) } & $6(8.2)$ & $9(15)$ & 0.21 \\
\hline \multicolumn{2}{|c|}{ Left ventricular ejection fraction (first month), \%, median (IQR) } & $60(50-60)$ & $60(55-62)$ & 0.06 \\
\hline \multicolumn{2}{|c|}{ Left ventricular diastolic diameter (first month), mm, median (IQR) } & $46(44-51.75)$ & $48(43-51)$ & 0.90 \\
\hline \multicolumn{2}{|c|}{ Left ventricular systolic diameter (first month), mm, median (IQR) } & $30(26-35.75)$ & $30(26-33)$ & $0.33^{\mathrm{a}}$ \\
\hline \multicolumn{2}{|c|}{ Left atrium diameter (first month), mm, mean (SD) } & $43.80(7.3)$ & $43.57(7.4)$ & 0.88 \\
\hline \multicolumn{2}{|c|}{ Aortic valve peak gradient (first month), mm Hg, median (IQR) } & $20(14-24)$ & $18(11.5-22.5)$ & $0.15^{\mathrm{a}}$ \\
\hline \multicolumn{2}{|c|}{ Aortic valve mean gradient (first month), mm Hg, median (IQR) } & $11(9-14)$ & $10(5.5-13)$ & $0.11^{\mathrm{a}}$ \\
\hline \multicolumn{2}{|c|}{ Systolic pulmonary arterial pressure (first month), mm Hg, median (IQR) } & $35(27-45)$ & $35(25-46)$ & \multirow[t]{3}{*}{$0.56^{\mathrm{a}}$} \\
\hline STS score, median (IQR) & $6(4-8)$ & $8(4.8-10.7)$ & $0.009^{\mathrm{a}}$ & \\
\hline Euroscore II, mean (SD) & $5.36(2.14)$ & $6.42(2.16)$ & 0.008 & \\
\hline \multirow[t]{3}{*}{ IMRS, n (\%) } & High & $26(35.6)$ & $27(45)$ & \multirow[t]{3}{*}{0.008} \\
\hline & Moderate & $33(45.2)$ & $32(53.3)$ & \\
\hline & Low & $14(19.1)$ & $1(1.6)$ & \\
\hline \multicolumn{2}{|c|}{ Decrease in platelet count, $\times 10^{9} / \mathrm{l}$, median (IQR) } & $108(77-154)$ & $108(59-141)$ & $0.47^{\mathrm{a}}$ \\
\hline
\end{tabular}

aMann-Whitney test performed IQR

Abbreviations: EuroSCORE, European System for Cardiac Operative Risk Evaluation Score; IMRS, InterMountain Risk Score; STS Score, The Society of Thoracic Surgeons risk scores; TAVI, transcatheter aortic valve implantation; other - see Table 1

patients were different between the two groups (Table 3). Otherwise, the use of general anesthesia in both groups was similar at $50 \%$. Two patients (one in survivors, one in non-survivors) had a vascular problem requiring intervention.

During the follow-up period, 2 patients $(2.7 \%)$ in Group 1 and 3 patients (5.0\%) in Group $2(P=0.49)$ were hospitalized due to heart failure.

A total of 60 patients died, of whom 19 died within 30 days, and 41 during the follow-up period.

A high IMRS was determined in 26 (35.6\%) patients in Group 1 and 27 (45\%) in Group 2; a moderate IMRS was determined in 33 (45.2\%) patients in Group 1 and 32 (53.3\%) in Group $2(P=0.008)$. The mean (SD) IMRS was $1.67(0.7)$ in Group 1 and $2.33(0.72)$ in Group $2(P<0.001)$. The median (IQR) STS score was 6 (4-8) in Group 1 and 8 (4.8-10.7) in Group $2(P=0.009)$, and the mean (SD). EuroSCORE II was 5.36 (2.14) in Group 1 and 6.42 (2.16) in Group $2(P=0.008)$ (Table 3).

Mean differences between the 2 groups in IMRS and EuroSCORE II were in terms of poor mobility, previous cardiac surgery, the New York Heart Association status, electrolytes ( $\mathrm{Na}, \mathrm{K}, \mathrm{Ca})$, and bicarbonate values.

Univariate analyses demonstrated that a low aortic peak gradient, EuroSCORE II and IMRS were risk factors for long-term mortality. Only high-risk IMRS (hazard ratio [HR], $3.430 ; 95 \%$ confidence interval $[\mathrm{Cl}], 1.537-7.653 ; P=0.003$ ) and EuroSCORE II (HR, 1.141; 95\% Cl, 1.011-1.288; $P=0.03)$ were independently associated with long-term mortality (Table 4).

The mean (SD) survival time was 1433 (124) days. The mean (SD) survival time distribution was 2103 (245) days in the group with low IMRS, 1426 (191) days in the group with moderate IMRS, and 912 (169) days in the group with high IMRS. The cumulative survival period decreased from low (mean [SD], 2103 [245] days) to high (mean [SD], 912 [169] days) in the IMRS score (Table 5). As seen in Figure 1, patients with high IMRS have a higher mortality rate during post-procedure TAVI follow-up.

\section{DISCUSSION}

The main aim of our study was to investigate the relationship between IMRS and the long-term mortality of patients undergoing TAVI.

In elderly patients, sSAS is the most common valve disease [12]. Surgical valve replacement is a good long-term treatment option for patients with sSAS, but in sSAS cases not treated due to high surgical risk, 50\% mortality due to SAS has been reported within 2 years of being symptomatic [13]. As a result of this, TAVI has become 
Table 4. Univariate analysis for estimating long-term mortality after transcatheter aortic valve implantation (TAVI). Low aortic peak gradient. EuroSCORE II and moderate/high risk Intermountain Risk Score have a predictive value for mortality during follow-up

\begin{tabular}{|c|c|c|c|c|}
\hline \multirow[t]{2}{*}{ Variable } & \multicolumn{2}{|c|}{ Univariate analysis } & \multicolumn{2}{|c|}{ Multivariable analysis } \\
\hline & HR $(95 \% \mathrm{CI})$ & $\boldsymbol{P}$-value & HR $(95 \% \mathrm{Cl})$ & $P$-value \\
\hline Low aortic peak gradient & $0.987(0.974-0.999)$ & 0.03 & $0.991(0.978-1.003)$ & 0.14 \\
\hline Edwards Sapiens ${ }^{\mathrm{TM}}$ valve & $1.899(0.807-4.469)$ & 0.14 & - & - \\
\hline Core valve $^{\mathrm{TM}}$ & $1.845(0.808-4.215)$ & 0.14 & - & - \\
\hline Moderate IMRS & $2.211(1.017-4.806)$ & 0.04 & $1.853(0.835-4.112)$ & 0.12 \\
\hline High IMRS & $3.967(1.875-8.392)$ & $<0.001$ & $3.430(1.537-7.653)$ & 0.003 \\
\hline STS Score & $1.084(0.999-1.176)$ & 0.05 & $1.021(0.933-1.118)$ & 0.65 \\
\hline EuroSCORE II & $1.149(1.018-1.297)$ & 0.02 & $1.141(1.011-1.288)$ & 0.03 \\
\hline
\end{tabular}

Variables with $P$-value $<0.1$ in univariate analysis evaluated in multivariable Cox regression analysis

Independent predictors for estimating the long-term mortality after TAVI. Only EuroSCORE II and High Risk Intermountain Risk Score have a predictive value for mortality during follow-up in multivariable Cox regression analysis

Abbreviations: $\mathrm{Cl}$, confidence interval; $\mathrm{HR}$, hazard ratio; other — see Tables 1 and 3

Table 5. Cumulative survival period for all three Intermountain Risk Scores (IMRS); survival probability decreases proportionally to IMRS

\begin{tabular}{l|c|c}
\multicolumn{1}{c|}{ Variable } & Mean (SD) & $\mathbf{9 5 \% ~ C I}$ \\
\hline Low IMRS, days & $2103(245)$ & $1622-2583$ \\
Moderate IMRS, days & $1426(191)$ & $1051-1801$ \\
High IMRS, days & $912(169)$ & $581-1243$ \\
Overall, days & $1433(124)$ & $1188-1677$ \\
\hline
\end{tabular}

Abrreviations: see Tables 3 and 4

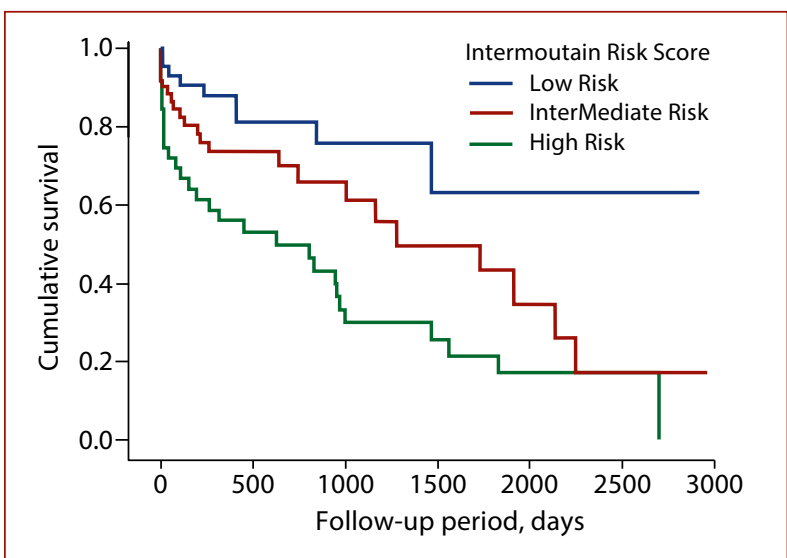

Figure 1. Survival function for the InterMountain Risk Score (IMRS); IMRS is associated with a high risk of transcatheter aortic valve implantation procedure mortality

the main alternative to surgical aortic valve replacement in SSAS patients, and with this development process, the number and spectrum of TAVI usage have increased [14]. As with all interventional procedures, an estimation of the patient's clinical and prognostic improvement with TAVI is very important when deciding on the procedure.

There are several risk scoring systems for appropriate patient selection for the TAVI procedure. After EuroSCORE was first published in 1999, it was revised in 2003 as the logistic EuroSCORE and was finally updated for better results in 2012 with a new model as EuroSCORE II [15-17].

The old STS score (2008 version) was based on patient data from 2002 to 2006 . The STS score was updated in 2018 to include several new parameters based on STS data from 2011 to 2016, which were the result of changes in surgical practice and patient clinical status [11].

During the early TAVI era, the combination of a logistic EuroSCORE $\geq 20 \%$ and STS score $>10 \%$ was used as a more realistic assessment of operative risk to better indicate the TAVI result and avoid the known overestimation of operative mortality of the EuroSCORE [18]. Following updates made to the EuroSCORE, the recent guidelines have recommended that STS or EuroSCORE $I \geq 4 \%$ or logistic EuroSCORE I $\geq 10 \%$ are suitable for TAVI in elderly patients [19].

The main benefits of these well-known, traditional risk scores are the prediction of patient mortality and disability, which help the physician define these problems and thereby select suitable patients for the procedure. However, it is unclear whether these well-known traditional risk scores are effective in the prediction of early and late mortality in patients.

The IMRS score was also updated in 2010 with the addition of the red cell distribution width [9]. May et al. presented the results of a study in which the IMRS was expanded with the inclusion of additional parameters such as albumin, bilirubin, and white cell differential count to improve the predictive ability of the risk score [20].

Many studies in the literature have presented mortality rates afterTAVI. Alpaslan et al. [21] reported 14.1\% in-hospital mortality, and in the current study, this rate was similarly at $14.2 \%(n=19)$.

There are also data on 30-day mortality. Svensson et al. [22] reported a rate of $3.4 \%$ for transfemoral TAVI patients, and in the study by Lareyre et al. [23], the rate was reported as $5.9 \%$. The higher rate in the current study could have been related to the low socio-cultural status of the patients.

In a review presented by Chakos et al. [24], survival at $1,2,3,5$ and 7 years were $83 \%, 75 \%, 65 \%, 48 \%$, and $28 \%$, respectively. In our study, we had a $54.9 \%(n=73)$ survival rate (mortality was $n=60 \%$ [45.1\%]) with a median follow-up period of 1279 days (3.5 years). With this value, we have a higher value than the study by Chakos et al. [24]. This may be caused by the fact that we had a more regular follow-up, which is related to better results in the long term. 
Female dominance was observed in the current study (Group 1: $n=44,60.3 \%$; Group 2: $n=35,58.3 \%$ ), which was similar to the findings of other studies [21, 25]. The mean age of the current study groups (Group 1, 78.38 [7.1] years; Group 2, 78.90 [7.9] years) was similar to the data of Makkar et al. [14].

For in-hospital, 30-day mortality, 8 patients died due to infection, one patient died due to pulmonary thromboembolism, 2 patients died due to stroke, 3 patients died due to progression of heart failure, and 5 patients died due to kidney injury. In long-term follow-up, 14 patients died due to cardiovascular events (progression of heart failure, sudden death, and stroke) and 27 patients died of non-cardiovascular causes (infections, progression of dementia, respiratory failure). The mean (SD) follow-up period in the current study was 1433 (124) days, and most deaths were due to non-cardiovascular causes, which was consistent with the findings of Salinas et al. [26]. In both groups, CIN due to the TAVI procedure, $\mathrm{DM}, \mathrm{HT}, \mathrm{AF}, \mathrm{CAD}$, preprocedural mean hemoglobin, mean serum creatinine, mean GFR, pre/post-procedural mean platelet values, pre-procedural median LVDD, LVSD, AVA, mean LA, IVS, Pw, MGR, SPAP, and first-month follow-up LVEF, LVSD, LA, PGR, MGR, and SPAP were similar and statistically non-significant.

In our study, there were no patients with a lowflow/low gradient among the survivors, but 4 patients in the non-survivor group had a low flow-low gradient. All the low flow/low gradient patients died. The increase in pressure overload of the myocardium results in myocardial hypertrophy and myocardial fibrosis associated with a peak gradient increase and myocardial injury/degeneration [27]. In contrast, low pre-procedural PGR (Group 1, 88.78 [22.72] $\mathrm{mm} \mathrm{Hg}$; Group 2, 79.17 [18.8] $\mathrm{mm} \mathrm{Hg} ; P=0.01$ ) was seen to be associated with increased mortality during the follow-up period. Takagi et al. [28] reported that patients with lowflow/low-gradient SAS had increased mortality compared with normal-flow/high-gradient SAS patients. In a similar situation, the presence of low PGR may be associated with increased mortality.

Several studies have demonstrated a relationship between a postprocedural platelet decrease and mortality with the TAVI procedure $[28,29]$. In the current study, there was no statistical significance difference in the median (IQR) platelet count decrease between survivors and nonsurvivors (108 [77-154] $\times 10^{9} / \mathrm{l}$ in Group 1 and 108 [59-141] $\times 10^{9} / \mathrm{l}$ in Group 2; $P=0.47$ ).

Hahn et al. [30] and Naqvi et al. [31] reported that peri-procedural TEE helps to provide intra-procedural guidance, predict and diagnose complications, and assists valve function, especially for difficult cases. In the current study, the peri-procedural TEE usage was found to be associated with mortality during the follow-up $(37 \%$ in Group $1 ; 18.3 \%$ in Group 2; $P=0.019)$, which is consistent with data in the literature. The TEE usage can lead to the selection of a more appropriate TAVI valve size and decrease procedure time, thereby reaching statistical significance due to increased success.

The main scoring systems widely used to predict the outcomes of cardiac surgery are the EuroSCORE II and the STS risk score $[5,6]$. If a patient has a high score in these scoring systems, the case is evaluated as a high surgical risk, and valve replacement may be applied with TAVI. Nevertheless, higher risk scores are known to have poor outcomes and lead to overestimation for the TAVI procedure [32, 33]. Yamaoka et al. [34] reported that EuroSCORE II had a better ability of calibration than the STS Score.

Average patient risk scores vary depending on the healthcare center. Yamaoka et al. [34] reported a mean EurOSCORE II of 3.1 and a mean STS score of 4.9 for operative mortality of TAVI patients, and Makkar et al. [14] reported a mean (SD) STS of 5.8 (2.1) for TAVI patients. In the current study, the median (IQR) STS score was 6 (4-8) in Group 1 and 8 (4.8-10.7) in Group 2, and the mean (SD) EuroSCORE II was 5.36 (2.14) in Group 1 and 6.42 (2.16) in Group 2. These scores are higher than those reported in the studies by Yamaoka et al. [34] and Makkar et al. [14].

New risk assessment methods have been investigated due to the limitations of classical risk factors. Alpaslan et al. [21] reported that male sex and pre-procedure low blood albumin levels were independent predictors of long-term mortality for TAVI. Afilalo et al. [35] showed that adding the frailty and disability scores to conservative scoring systems can improve the predictions of mortality or morbidity in elderly patients undergoing cardiac surgery.

In this context, this study aimed to evaluate the effect of different risk scores on mortality following the TAVI procedure.

The IMRS was developed to evaluate individual mortality using the complete blood count and a metabolic profile of patients [8]. The IMRS includes a spectrum of general medical risks. This risk stratification tool can predict various diseases that result in mortality, including cardiac pathologies [9]. Most clinical risk scores have difficult calculation methods due to the complex data requirements. As the IMRS only requires the data of common laboratory tests, an IMRS web calculator is also available with free access [10]. Johnson et al. $[36,37]$ reported that IMRS strongly predicted death in coronary artery bypass patients and significantly predicts mortality in coronary artery disease patients divided into the percutaneous treatment and medical therapy groups.

In the current study, univariate analyses demonstrated that low aortic peak gradient $(\mathrm{HR}, 0.987 ; 95 \% \mathrm{Cl}$, 0.974-0.999; $P=0.04)$, EuroSCORE II (HR, 1.149; $95 \% \mathrm{Cl}$, $1.018-1.297 ; P=0.02)$ and a moderate $(\mathrm{HR}, 2.211 ; 95 \% \mathrm{Cl}$, 1.017-4.806; $P=0.04)$ - high (HR, 3.967; 95\% Cl, 1.875$-8.392 ; P<0.001)$ risk of IMRS are associated with long-term mortality. However, in multivariable analysis, only the high risk of IMRS (HR, 3.430;95\% Cl, 1.537-7.653; $P=0.003)$ and EuroSCORE II $(\mathrm{HR}, 1.141 ; 95 \% \mathrm{Cl}, 1.011-1.288 ; P=0.03)$ were 
found to independently predict long-term mortality. Low PGR was not seen to have predictive value for mortality following the TAVI procedure (Table 4).

In accordance with the purpose and data of our study, considering the mean survival time of the high, medium, and low groups according to the IMRS classification during the total follow-up period, it was 2103 days in the group with low IMRS, 1426 days in the group with moderate IMRS, and only 912 days in the group with high IMRS (Table 5). These data also show that IMRS is relevant for each risk group in predicting life expectancy in patients and thus predicting mortality.

Based on all laboratory and echocardiography parameters, it was observed that long-term mortality (>30 days) for the TAVI procedure was higher in the patients with high IMRS and EuroSCORE II. Furthermore, the fact that long-term mortality was higher in the patients with moderate and high IMRS scores than in those with low scores suggests that the IMRS is promising as a scoring system for patient selection for the TAVI procedure in addition to the well-known traditional risk scores. Therefore, our data can be considered important in demonstrating the clinical significance of IMRS calculation before the TAVI procedure.

\section{Limitations}

The limitation of this study was that it was conducted retrospectively in a single center.

\section{CONCLUSIONS}

When commonly used risk factor systems are insufficient, the calculation of IMRS before the TAVI procedure may be useful in predicting long-term mortality after TAVI because it uses different risk factors than those in other commonly used scoring systems. Thus, the IMRS can provide new insights for the prediction of patient outcomes following TAVI, and it may be useful for identifying patients who will benefit from the TAVI procedure in the long term.

Larger scale evaluations are needed to confirm the findings of this study, which included a limited number of patients from a single center.

\section{Article information}

Conflict of interest: None declared.

Open access: This article is available in open access under Creative Common Attribution-Non-Commercial-No Derivatives 4.0 International (CC BY-NC-ND 4.0) license, allowing to download articles and share them with others as long as they credit the authors and the publisher, but without permission to change them in any way or use them commercially. For commercial use, please contact the journal office at kardiologiapolska@ptkardio.pl.

How to cite: Özdemir E, Esen Ş, Emren SV, et al. Association between Intermountain Risk Score and long-term mortality with the transcatheter aortic valve Implantation procedure. Kardiol Pol. 2021; 79(11): 1215-1222, doi: 10.33963/KP.a2021.0120.

\section{REFERENCES}

1. Cribier A, Eltchaninoff $\mathrm{H}$, Bash $\mathrm{A}$, et al. Percutaneous transcatheter implantation of an aortic valve prosthesis for calcific aortic stenosis: first human case description. Circulation. 2002; 106(24): 3006-3008, doi: 10.1161/01. cir.0000047200.36165.b8, indexed in Pubmed: 12473543.

2. Leon MB, Smith CR, Mack M, et al. PARTNER Trial Investigators. Transcatheter aortic-valve implantation for aortic stenosis in patients who cannot undergo surgery. N Engl J Med. 2010; 363(17): 1597-1607, doi: 10.1056/NEJMoa1008232, indexed in Pubmed: 20961243.

3. Pascual I, Hernández-Vaquero D, Alperi $A$, et al. Survival in elderly patients with transcatheter aortic valve implants compared with the general population. Rev Esp Cardiol (Engl Ed). 2020; 73(10): 822-827, doi: 10.1016/j. rec.2019.10.027, indexed in Pubmed: 32147402.

4. van MourikMS, VendrikJ, Abdelghani M, et al. Guideline-defined futility or patient-reported outcomes to assess treatment success after TAVl: what to use? Results from a prospective cohort study with long-term follow-up. Open Heart. 2018; 5(2): e000879, doi: 10.1136/openhrt-2018-000879, indexed in Pubmed: 30275957.

5. O'Brien SM, Shahian DM, Filardo G, et al. Society of Thoracic Surgeons Quality Measurement Task Force. The Society of Thoracic Surgeons 2008 cardiac surgery risk models: part 2 isolated valve surgery. Ann Thorac Surg. 2009; 88(Suppl 1): S23-S42, doi: 10.1016/j. athoracsur.2009.05.056, indexed in Pubmed: 19559823.

6. Baldasseroni S, Pratesi A, Orso F, et al. Role of frailty on risk stratification in cardiac surgery and procedures. Adv Exp Med Biol. 2020; 1216: 99-113, doi: 10.1007/978-3-030-33330-0_11, indexed in Pubmed: 31894551.

7. Biancari F, Juvonen T, Onorati $F$, et al. Meta-analysis on the performance of the EuroSCORE II and the Society of Thoracic Surgeons Scores in patients undergoing aortic valve replacement. J Cardiothorac Vasc Anesth. 2014; 28(6): 1533-1539, doi: 10.1053/j.jvca.2014.03.014, indexed in Pubmed: 25263775.

8. Horne BD, May HT, Muhlestein JB, et al. Exceptional mortality prediction by risk scores from common laboratory tests. Am J Med. 2009; 122(6): 550 558, doi: 10.1016/j.amjmed.2008.10.043, indexed in Pubmed: 19486718.

9. Horne BD, May HT, Kfoury AG, et al. The Intermountain Risk Score (including the red cell distribution width) predicts heart failure and other morbidity endpoints. Eur J Heart Fail. 2010; 12(11): 1203-1213, doi: 10.1093/eurjhf/hfq115, indexed in Pubmed: 20705688.

10. Intermountain Healthcare, Utah, USA. https://intermountainhealthcare. org/IMRS/ (May 1, 2020).

11. Hensey M, Sathananthan J, Murdoch DJ, et al. Assessment of updated Society of Thoracic Surgeons score in historical PARTNER II patients. J Am Coll Cardiol. 2019; 73(23):3032-3034, doi: 10.1016/j.jacc.2019.03.498, indexed in Pubmed: 31196463.

12. Nkomo VT, Gardin JM, Skelton TN, et al. Burden of valvular heart diseases: a population-based study. Lancet. 2006; 368(9540): 1005-1011, doi: 10.1016/S0140-6736(06)69208-8, indexed in Pubmed: 16980116.

13. Ross J, Braunwald E. Aortic stenosis. Circulation. 1968; 38(1 Suppl):61-67, doi: 10.1161/01.cir.38.1s5.v-61, indexed in Pubmed: 4894151.

14. Makkar R, Thourani V, Mack M, et al. Five-year outcomes of transcatheter or surgical aortic-valve replacement. N Engl J Med. 2020; 382(9): 799-809, doi: 10.1056/nejmoa1910555, indexed in Pubmed: 31995682.

15. Roques F, Nashef SA, Michel P, et al. Risk factors and outcome in European cardiac surgery: analysis of the EuroSCORE multinational database of 19030 patients. Eur J Cardiothorac Surg. 1999; 15(6): 816-822, doi: 10.1016/s1010-7940(99)00106-2, indexed in Pubmed: 10431864.

16. Roques F, Michel P, Goldstone AR, et al. The logistic EuroSCORE. Eur Heart J. 2003; 24(9): 881-882, doi: 10.1016/s0195-668x(02)00799-6, indexed in Pubmed: 12727160 .

17. Nashef SAM, Roques F, Sharples LD, et al. EuroSCORE II. Eur J Cardiothorac Surg. 2012; 41(4): 734-745, doi: 10.1093/ejcts/ezs043, indexed in Pubmed: 22378855.

18. Vahanian A, Alfieri $O$, Andreotti F, et al. Guidelines on the management of valvular heart disease (version 2012) The Joint Task Force on the Management of Valvular Heart Disease of the European Society of Cardiology (ESC) and the European Association for Cardio-Thoracic Surgery (EACTS). Eur Heart J. 2012; 33(19): 2451-2496, doi: 10.1093/eurheartj/ehs109, indexed in Pubmed: 22922415.

19. Baumgartner H, Falk V, Bax JJ, et al. ESC Scientific Document Group. 2017 ESC/EACTS Guidelines for the management of valvular heart disease. Eur Heart J. 2017; 38(36): 2739-2791, doi: 10.1093/eurheartj/ehx391, indexed in Pubmed: 28886619. 
20. May HT, Anderson JL, Muhlestein JB, et al. Improvement in the predictive ability of the Intermountain Mortality Risk Score by adding routinely collected laboratory tests such as albumin, bilirubin, and white cell differential count. Clin Chem Lab Med. 2016; 54(10): 1619-1628, doi: 10.1515/cclm-2015-1258, indexed in Pubmed: 27101550.

21. Alpaslan E, Dursun $H$, Tanriverdi Z, et al. New risk factors in determining longterm mortality in patients undergoing TAVI: can the conventional risk scores be used as a longterm mortality predictor? Kardiol Pol. 2020; 78(3): 219-226, doi: 10.33963/KP.15183, indexed in Pubmed: 32041928.

22. Svensson LG, Tuzcu M, Kapadia S, et al. A comprehensive review of the PARTNER trial. J Thorac Cardiovasc Surg. 2013; 145(3 Suppl): S11-S16, doi: 10.1016/j.jtcvs.2012.11.051, indexed in Pubmed: 23410766

23. Lareyre F, Raffort J, Dommerc C, et al. A 7-year single-center experience of transfemoral TAVI: evolution of surgical activity and impact on vascular outcome. Angiology. 2018; 69(6): 532-539, doi: 10.1177/0003319717737665, indexed in Pubmed: 29105493.

24. Chakos A, Wilson-Smith A, Arora S, et al. Long term outcomes of transcatheter aortic valve implantation (TAVI): a systematic review of 5-year survival and beyond. Ann Cardiothorac Surg. 2017; 6(5): 432-443, doi: 10.21037/acs.2017.09.10, indexed in Pubmed: 29062738.

25. Saia F, Latib A, Ciuca C, et al. Causes and timing of death during longterm follow-up after transcatheter aortic valve replacement. Am Heart J. 2014; 168(5): 798-806, doi: 10.1016/j.ahj.2014.07.023, indexed in Pubmed: 25440810.

26. Salinas $\mathrm{P}$, Moreno R, Calvo L, et al. Long-term follow-up after transcatheter aortic valve implantation for severe aortic stenosis. Rev Esp Cardiol (Engl Ed). 2016; 69(1): 37-44, doi: 10.1016/j.rec.2015.03.017, indexed in Pubmed: 26234997.

27. Hein S, Arnon E, Kostin S, et al. Progression from compensated hypertrophy to failure in the pressure-overloaded human heart: structural deterioration and compensatory mechanisms. Circulation. 2003; 107(7): 984-991, doi: 10.1161/01.cir.0000051865.66123.b7, indexed in Pubmed: 12600911.

28. Takagi H, Hari Y, Nakashima K, et al. ALICE (All-Literature Investigation of (ardiovascular Evidence) Group. Impact of postprocedural thrombocytopenia on mortality after transcatheter aortic valve implantation. J Cardiovasc Med (Hagerstown). 2020; 21(4): 318-324, doi: 10.2459/JCM.0000000000000949, indexed in Pubmed: 32108127.
29. Kalińczuk $Ł$, Zieliński K, Chmielak Z, et al. Effect on mortality of systemic thromboinflammatory response after transcatheter aortic valve implantation. Am J Cardiol. 2019; 124(11): 1741-1747, doi: 10.1016/j. amjcard.2019.08.036, indexed in Pubmed: 31590911.

30. Hahn RT. Guidance of transcatheter aortic valve replacement by echocardiography. Curr Cardiol Rep. 2014; 16(1): 442, doi: 10.1007/s11886-0130442-7, indexed in Pubmed: 24293358.

31. Naqvi TZ. Echocardiography in transcatheter aortic (Core)Valve implantation: Part 2-Transesophageal echocardiography. Echocardiography. 2018; 35(7): 1020-1041, doi: 10.1111/echo.14034, indexed in Pubmed: 29981214.

32. Chmielak Z, Witkowski A, Dabrowski M, et al. Comparison of mid-term results of transcatheter aortic valve implantation in high-risk patients with logistic EuroSCORE $\geq 20 \%$ or <20. Kardiol Pol. 2016; 74(3): 224-230, doi: 10.5603/KP.a2015.0161, indexed in Pubmed: 26305367.

33. Hemmann K, Sirotina M, De Rosa S, et al. The STS score is the strongest predictor of long-term survival following transcatheter aortic valve implantation, whereas access route (transapical versus transfemoral) has no predictive value beyond the periprocedural phase. Interact Cardiovasc Thorac Surg. 2013; 17(2): 359-364, doi: 10.1093/icvts/ivt132, indexed in Pubmed: 23644728.

34. Yamaoka H, Kuwaki $\mathrm{K}$, Inaba $\mathrm{H}$, et al. Comparison of modern risk scores in predicting operative mortality for patients undergoing aortic valve replacement for aortic stenosis. J Cardiol. 2016; 68(2): 135-140, doi: 10.1016/j.jjcc.2015.08.017, indexed in Pubmed: 26411253.

35. Afilalo J, Mottillo S, Eisenberg MJ, et al. Addition of frailty and disability to cardiac surgery risk scores identifies elderly patients at high risk of mortality or major morbidity. Circ Cardiovasc Qual Outcomes. 2012; 5(2): 222-228, doi: 10.1161/CIRCOUTCOMES.111.963157, indexed in Pubmed: 22396586.

36. Johnson EG, Lappe D, Anderson J, et al. Patient mortality following coronary bypass surgery is strongly predicted by the Intermountain Risk Score. J Am Coll Cardiol. 2013; 61(10): E1606, doi: 10.1016/s07351097(13)61606-x.

37. Johnson EG, Anderson JL, Lappé DL, et al. The Intermountain Risk Score predicts mortality and cardiovascular events among coronary disease patients treated by percutaneous or medical interventions. Circulation. 2012; 126: A13381. 